\title{
The expression of petunia strigolactone pathway genes is altered as part of the endogenous developmental program
}

\author{
Revel S. M. Drummond ${ }^{1}$, Hester Sheehan ${ }^{1,2}$, Joanne L. Simons ${ }^{1}$, N. Marcela Martínez-Sánchez ${ }^{1}$, \\ Rebecca M. Turner ${ }^{1}$, Joanna Putterill ${ }^{2}$ and Kimberley C. Snowden ${ }^{1 *}$ \\ 'The New Zealand Institute for Plant and Food Research Ltd, Auckland, New Zealand \\ 2 Plant Molecular Sciences, School of Biological Sciences, University of Auckland, Auckland, New Zealand
}

\section{Edited by:}

Michael J. Scanlon, Cornell University,

USA

\section{Reviewed by:}

Darleen Audrey DeMason, University of California Riverside, USA

Dan Chitwood, University of California Davis, USA

*Correspondence:

Kimberley C. Snowden, The New Zealand Institute for Plant and Food Research Ltd, 120 Mount Albert

Road, Sandringham 1025, Auckland, New Zealand.

e-mail:kimberley.snowden@ plantandfood.co.nz
Analysis of mutants with increased branching has revealed the strigolactone synthesis/perception pathway which regulates branching in plants. However, whether variation in this well conserved developmental signaling system contributes to the unique plant architectures of different species is yet to be determined. We examined petunia orthologs of the Arabidopsis MAX1 and MAX2 genes to characterize their role in petunia architecture. A single ortholog of MAX1, PhMAX1 which encodes a cytochrome P450, was identified and was able to complement the max 1 mutant of Arabidopsis. Petunia has two copies of the MAX2 gene, PhMAX2A and PhMAX2B which encode F-Box proteins. Differences in the transcript levels of these two MAX2-like genes suggest diverging functions. Unlike PhMAX2B, PhMAX2A mRNA levels change in leaves of differing age/position on the plant. Nonetheless, this gene functionally complements the Arabidopsis max2 mutant indicating that the biochemical activity of the PhMAX2A protein is not significantly different from MAX2. The expression of the petunia strigolactone pathway genes (PhCCD7, PhCCD8, PhMAX1, PhMAX2A, and PhMAX2B) was then further investigated throughout the development of wild-type petunia plants. Three of these genes showed changes in mRNA levels over a development series. Alterations to the expression patterns of these genes may influence the branching growth habit of plants by changing strigolactone production and/or sensitivity. These changes could allow both subtle and dramatic changes to branching within and between species.

Keywords: Arabidopsis, axillary branching, strigolactone, dad, development, max, petunia

\section{INTRODUCTION}

Vegetative branching involves the production of new growth axes from axillary meristems. Coordinating the growth of these meristems across the body of the plant is vital to a plant's reproductive success and its ability to recover from herbivory and other damage. The study of branching mutants in different plant systems can provide insights into the conservation and diversity of branching control systems. In petunia (Petunia hybrida), branching occurs in two distinct phases (Snowden and Napoli, 2003). During vegetative development branches are generally produced acropetally from nodes 3-8 on the main stem. Basal branching ceases at or before the floral transition, with the axillary meristems above node eight not developing beyond small buds. The petunia inflorescence is then produced by a series of sympodial branches, while at the same time additional lateral branches develop in a basipetal wave down the main stem from the node immediately below the first flower (Snowden and Napoli, 2003; Drummond et al., 2009b).

Branching in Arabidopsis (Arabidopsis thaliana), pea (Pisum sativum), and rice (Oryza sativa) is also well studied, particularly under conditions that promote flowering. Differences are observed in the branching that occurs in these species (and petunia), particularly with respect to the timing of branching or the positioning of branches along the main shoot axis (Figure 1). For example,
Arabidopsis tends to produce branches in a basipetal wave after the floral transition (Hempel and Feldman, 1994) though axillary meristems can produce vegetative buds in an acropetal wave from basal nodes of the plant in some circumstances (Stirnberg et al., 1999). Rice produces branches (known as tillers) during vegetative growth (Hanada, 1993) and tall, wild-type cultivars of pea branch from the nodes immediately basipetal to the first flower (Stafstrom, 1995). For many species, differences occur in growth habit between cultivars. In different petunia cultivars, the number of nodes that produce branches can vary, as well as the positioning of the basal branches along the shoot axis (Brunaud et al., 1977; Drummond et al., 2009b).

The decreased apical dominance (dad)/more axillary growth ( $\max ) /$ ramosus $(\mathrm{rms}) / d w a r f(d ;$ petunia/Arabidopsis/pea/rice) mutants have an increased number of vegetative branches and decreased plant height compared to wild-type plants (Blixt, 1976; Napoli and Ruehle, 1996; Stirnberg et al., 2002; Ishikawa et al., 2005). The petunia $d a d 1$ and $d a d 2$ mutants have a similar mutant phenotype, these plants have decreased height and in most growth conditions produce branches from every axillary meristem on the main shoot before flowering (Snowden and Napoli, 2003). A large number of secondary branches and a smaller number of tertiary branches are also produced. The dad 3 mutant has a less severe 

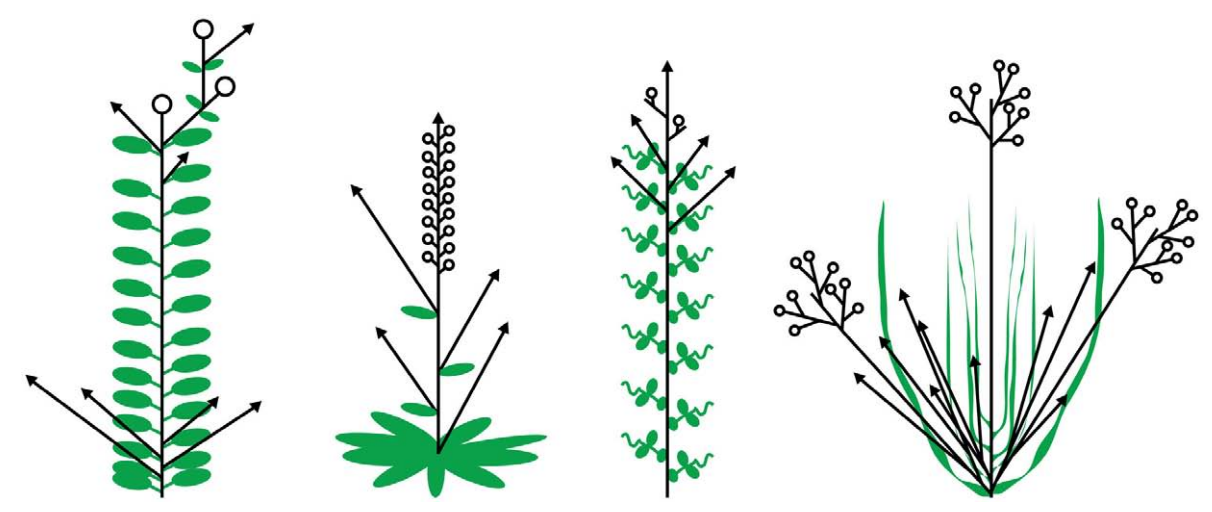

FIGURE 1 | Growth habit of petunia, Arabidopsis, pea, and rice. Branching patterns are shown for (from left to right) petunia, Arabidopsis, pea, and rice. Leaves are shown in green, open circles represent flowers, and arrows represent branches.

mutant phenotype, which in some growth conditions is overlapping with that of wild-type, although the mutants frequently produce secondary branches when wild-type does not. There are other changes to the plants in each species, such as delayed leaf senescence, delayed flowering time, and decreased root mass. The severity of change in these characters varies depending on the species and the particular gene (Woo et al., 2001; Snowden et al., 2005).

It is now apparent that the carotenoid cleavage dioxygenase (CCD) genes CCD7 and CCD8 are important components in the regulation of axillary branching. These genes when disrupted give rise to the dad3/max3/rms5/htd 1 and the dad1/max $4 / \mathrm{rms} 1 / \mathrm{d} 10$ mutants respectively (Sorefan et al., 2003; Booker et al., 2004; Snowden et al., 2005; Zou et al., 2005; Johnson et al., 2006; Arite et al., 2007; Drummond et al., 2009c). The CCD7 and CCD8 proteins are required for the production of the plant hormone strigolactone (Gomez-Roldan et al., 2008; Umehara et al., 2008). Strigolactones are a class of naturally occurring compounds (Yoneyama et al., 2008), thought to be derived from carotenoids (Matusova et al., 2005). Strigolactones were first identified as germination stimulants for parasitic weeds (Cook et al., 1966; Siame et al., 1993; Yokota et al., 1998) and they have also been shown to be important for the establishment of the plant/arbuscular mycorrhizal fungi symbiosis (Akiyama et al., 2005). The addition of strigolactone to $c c d 7$ or $c c d 8$ mutant plants of rice, pea, and Arabidopsis suppresses branching to wild-type levels identifying these compounds as an endogenous plant growth signal (Gomez-Roldan et al., 2008; Umehara et al., 2008).

Two additional genes were identified in mutant screens in Arabidopsis that are involved in the control of branching, these are AtMAX1 and AtMAX2 (Stirnberg et al., 2002; Booker et al., 2005). The MAX1 protein is a cytochrome P450 monooxygenase and has been suggested to modify the strigolactone signal molecule (Booker et al., 2005). The MAX2 protein is a member of the F-box LRR_7 family and is thought to be involved in the reception of strigolactone, or to be involved in its signal transduction, in the stem or the axillary bud (Stirnberg et al., 2002). Part of the reasoning for placing the AtMAX2 gene in signal reception is that the $\max 2$ mutant, unlike the other max mutants, is unable to be reverted by grafting the mutant scion to wild-type rootstocks, a feature that it shares with the dad 2 mutant of petunia (Booker et al., 2005; Simons et al., 2007). The AtMAX2 gene has been reported to play a role in two additional developmental processes; leaf senescence and seedling morphogenesis (Woo et al., 2001; Shen et al., 2007).

Senescence of leaves is the last stage of their developmental program. It is an orderly process that recycles much of the content of the dying leaves into the growing parts of the plant (reviewed in Lim et al., 2007). Senescence is frequently triggered by stresses, such as nutrition shortages, and high or low light. However, a large number of delayed leaf senescence mutants have been identified in Arabidopsis (Lim et al., 2007) including one with a mutation in AtMAX2 (Woo et al., 2001). In petunia delayed leaf senescence has been reported for the dad1 mutant (Snowden et al., 2005) and kiwifruit plants with CCD8 knocked down by RNAi have delayed leaf senescence (Ledger et al., 2010).

The endogenous developmental program that regulates branching determines whether growth will occur by integrating the timing, position, and identity of axillary meristems (Bell, 1991). In petunia this produces a zone of branches on the lower part of the main stem (Snowden and Napoli, 2003). The petunia dad mutants are altered in the timing and/or position of branch growth (Napoli and Ruehle, 1996). This suggests that the strigolactone signaling system may regulate branching during the development of petunia. Not all components of the strigolactone biosynthesis and perception pathway have been identified in petunia, and it is unknown whether all genes in the pathway are conserved. Our aim is to identify any orthologs of the MAX1 and MAX2 genes in petunia, and to determine whether the transcript abundance patterns of these and other branching genes are involved in determining the branching pattern of petunia. The possibility that a MAX2 ortholog could be the as yet unidentified $D A D 2$ gene was also explored.

We have identified genes orthologous to MAX1 and MAX2 in petunia - PhMAX1, PhMAX2A and PhMAX2B and show that these genes are expressed in a range of organs in mature wild-type and dad mutant petunia. We have also determined the transcript profiles of five genes involved in either strigolactone synthesis or 
reception across whole-plant development and during leaf senescence and observed time dependent changes in steady state mRNA levels for four of the genes. This suggests that although the genetic system that controls the production and reception of the hormone strigolactone is conserved, the detailed regulation of these genes may lead to the observed differences in plant form.

\section{MATERIALS AND METHODS GENETIC STOCKS, TRANSFORMATION, AND PLANT GROWTH CONDITIONS}

The dad mutants were derived from P. hybrida inbred line V26 (petunia) by Napoli and Ruehle (1996). The A. thaliana (Arabidopsis) $\max 1$ and $\max 2$ mutants were derived from ecotype Columbia and were kindly donated by O. Leyser. Petunia was transformed as described by Jorgensen et al. (1996), modified to remove acetosyringone from the co-cultivation medium. Transformation efficacy was assessed by the parallel introduction of a control construct, pHEX4 (Drummond et al., 2009c). Thirteen lines of wild-type petunia stably transformed with 35S-RNAi-PhMAX1 and 19 lines transformed with 35S-RNAi-PhMAX2A were produced. Four lines of 35S-RNAi-PhMAX1 and three lines of 35S-RNAi-PhMAX2A showed a possible alteration to the branching phenotype and were taken to the T2 generation. The segregating populations were screened by PCR for the presence of the transgene. Arabidopsis was transformed as described by Clough and Bent (1988), with the minor modification that the Agrobacterium cultures were applied to individual flowers in $10-\mu \mathrm{L}$ drops. For phenotypic characterization, all plants were grown in soil in a glasshouse as described in Snowden et al. (2005), unless otherwise stated in the text.

\section{GENE ISOLATION}

We identified MAX1 and MAX2 homologous genes from public sequence databases using BLAST. Alignments of the protein sequences that were identified were used to find regions of conservation in each gene and degenerate primers were designed to those regions. Two fragments of PhMAX1 were isolated using the degenerate primer pairs oM1-1/oM1-2, and oM1-3/oM1-4 (Table 1). The PCR cycling conditions were $94^{\circ} \mathrm{C}$ for $2 \mathrm{~min}$, followed by 30 cycles of $94^{\circ} \mathrm{C}$ for $15 \mathrm{~s}, 60^{\circ} \mathrm{C}$ for $30 \mathrm{~s}, 72^{\circ} \mathrm{C}$ for $2 \mathrm{~min}$, followed by $72^{\circ} \mathrm{C}$ for $5 \mathrm{~min}$. The first fragment of PhMAX2A was isolated using the primers oM $2 \mathrm{~A}-1 / \mathrm{oM} 2 \mathrm{~A}-2$ (Table 1). The PCR cycling conditions were $94^{\circ} \mathrm{C}$ for $2 \mathrm{~min}$, followed by 30 cycles of $94^{\circ} \mathrm{C}$ for $15 \mathrm{~s}, 55^{\circ} \mathrm{C}$ for $30 \mathrm{~s}, 72^{\circ} \mathrm{C}$ for $1 \mathrm{~min}$, followed by $72^{\circ} \mathrm{C}$ for $5 \mathrm{~min}$. The reaction mixes contained Platinum Taq (Invitrogen) with all components as per the manufacturer's recommendations, except that primers were added to a final concentration of $10 \mu \mathrm{M}$ for PhMAX1 and $1 \mu \mathrm{M}$ for PhMAX2A (to allow for the high redundancy of these primers). Petunia genomic DNA was used as the template for both reactions. A fragment of the PhMAX2B sequence was identified in the 454PetuniaDB sequence database (Zenoni et al., 2011). An iterative process of cloning, sequencing, RT-PCR, and inverse PCR (iPCR; Snowden and Napoli, 1998) was used to isolate the remainder of the genes' sequence.

\section{BIOINFORMATICS}

Sequences with similarity to known genes were identified in the GenBank and 454PetuniaDB databases using the BLAST algorithm. Sequences were aligned using either ClustalX or Geneious ${ }^{\circledR}$ alignment (Drummond et al., 2009a). Maximum likelihood phylogenies were calculated using the PhyML (Guindon and Gascuel, 2003) algorithm as implemented in Geneious ${ }^{\circledR}$. Bootstrap values were calculated as a confidence measure in the phylogenies using 1000 replicates.

\section{VECTOR CONSTRUCTION}

To overexpress the PhMAX1 gene its full-length cDNA, amplified using the oM1-5/oM1-6 primer pair (Table 1), was cloned into the pSAK778 vector (Drummond et al., 2009c) immediately $3^{\prime}$ of the $35 \mathrm{~S}$ promoter in that vector. Similarly the full-length cDNA of PhMAX2A was amplified using the oM2A-3/oM2A-4 primer pair (Table 1), and cloned into the pART277 vector (Gleave, 1992) again immediately $3^{\prime}$ of a $35 \mathrm{~S}$ promoter.

Table 1 | DNA primer pairs used in this research.

\begin{tabular}{|c|c|}
\hline Primer pair names & Primer sequences \\
\hline oM1-1/oM1-2 & GCNGTIACNTAYGARCAYCTICTNGCNGG/TCNGGYTCIGGRAARTTYTTNGGRTCYTT \\
\hline oM1-3/oM1-4 & GATGACCAGCGACTAGATAG/ACNGAYGTIATHGGNCARGCNGCNTTYGG \\
\hline oM1-5/oM1-6 & CGGGATCCCGATCTCCTTCTCCATCAAGAG/CCGCTCGAGCGGCGTAGAGCTTCTTCTGAG \\
\hline oM1-7/oM1-8 & $\begin{array}{l}\text { GGGGACAAGTTTGTACAAAAAAGCAGGCTGGACTCTCCAAACCAATAAC/GGGGACCACTTTGTACAAGAAAGCTGGGTG } \\
\text { TGATCATCAGGGCCAAAAG }\end{array}$ \\
\hline oM1-9/oM1-10 & GAGGTGGAGATTGGAGGCTAT/TTCTCTGGTTCAGGGAAGTTCT \\
\hline oM1-11/oM1-12 & GCTGTCTACCCATATGGAATC/CGGGATCCCGATCTCCTTCTCCATCAAGAG \\
\hline oM1-13/oM1-14 & GTTGGCTCTTGGAGTTCTTG/CCGCTCGAGCGGCGTAGAGCTTCTTCTGAG \\
\hline oM2A-1/oM2A-2 & GATIIAAGGIGATTGCAG/GGTGGCCAATAATCIAGITC \\
\hline oM2A-3/oM2A-4 & CACTCGAGCAACACCTGTGACTGATTGCT/GCTCTAGACCAATTTGCACAAAGTGCACC \\
\hline oM2A-5/oM2A-6 & $\begin{array}{l}\text { GGGGACAAGTTTGTACAAAAAAGCAGGCTAAGAAGCGATGCAAGTTCTCC/GGGACCACTTTGTACAAGAAAGCTGGGTG } \\
\text { CTCAAAGTTCCAATCCCAAG }\end{array}$ \\
\hline oM2A-7/oM2A-8 & TCCATTGCCATGTCCATTGAC/CAGCTTTGTCCAACTCTAGG \\
\hline oM2A-9/oM2A-10 & CTACAAGAATGCCTCACGCTC/ATAGTAATCCTCTCTCAGTTGCAC \\
\hline oM2B-1/oM2B-2 & GCTCAGAAAGTTGTTCATCCATG/TGCCGGGTAGTAATCTTCTCTC \\
\hline oCAB-1/oCAB-2 & CGGACTTGACTACTTGGGCAAC/GCAACACGGTAACCCTCAAC \\
\hline
\end{tabular}


To knockout the expression of the PhMAX1 gene, a fragment of the gene was amplified using the oM1-7/oM1-8 primer pair (Table 1). These primers have $5^{\prime}$ extensions consisting of the AttB1/AttB2 Gateway ${ }^{\circledR}$ cloning sites. The amplified product was Gateway cloned into pDONR221 and from there into pTKO2 (Snowden et al., 2005). A construct designed to knockout PhMAX2A expression was created in the same way starting with the oM2A-5/oM2A-6 primer pair (Table 1).

\section{SOUTHERN ANALYSIS}

Southern analysis of MAX2 copy number was carried out using $10 \mu \mathrm{g}$ of restriction enzyme-digested petunia genomic DNA with radioactive probes, as described in Snowden and Napoli (1998). The probe was created from a PCR fragment amplified using the oM2A-7/oM2A-8 primer pair (Table 1). The analysis of PhMAX1 was carried out using a similar method but with the radioactive probes replaced with the digoxigenin labeling system (Roche), and following the manufacturer's instructions. The probes were created from PCR products; probe 1 was produced using the oM1-11/oM1-12 primer pair, probe 2 using the oM1-13/oM114 primer pair (Table 1). The positive control was linearized pGEM-T Easy plasmid carrying the PhMAX1 cDNA (expected size $4.7 \mathrm{~kb})$. All washes of Southern blots were performed at medium to high stringency $\left(0.5-0.1 \times \mathrm{SSC}, 65^{\circ} \mathrm{C}\right)$ to allow the detection of homologous sequences.

\section{QUANTITATIVE RT-PCR}

The samples used in quantitative RT-PCR (qPCR) analyses were collected from at least six individual plants grown in a glasshouse and the tissue pooled before RNA isolation. All experiments contain at least two biological replicates, where a second population of plants were grown, and the RNA isolated, independently from the first. We show the biological replicate data in Figures $\mathbf{4}$ and $\mathbf{8}$ as some differences were noted between replicates (discussed in the main text). The wild-type samples for the experiment shown in Figure 4 were collected from plants that had been grown in a glasshouse, the first replicate in late winter, and the second in spring. The development series plants (Figure 8) were grown in a glasshouse over summer, with the replicate start dates offset by 1 week. The data in Figure 4 was derived from the following samples: fine lateral roots, $\mathrm{R}$; low internodes (below node five) on the main stem LIN; nodes 3-4 on the main stem, N; high internodes (above node 12) on the main stem, HIN; fully expanded leaves, L; axillary bud, AXB; shoot apex, SA. The SA sample contained the shoot apical meristem and approximately $5 \mathrm{~mm}$ of stem and associated young leaves. All stem samples had leaves and associated axillary buds removed. The data in Figure 5 was derived from: fine lateral roots, $\mathrm{R} ; 2 \mathrm{~cm}$ of stem above the cotyledons (nodes and internodes), S; axillary bud, AXB; shoot apex, SA. The data in Figure 6 was derived from three experiments. In Experiment 1 leaves were sampled from four positions on the plants; position A is $1 \mathrm{~cm}$ above the cotyledons, position $\mathrm{D}$ is two nodes below the first flower, positions $\mathrm{B}$ and $\mathrm{C}$ are equally spaced between these samples. In Experiments 2 and 3 leaves were sampled at four nodes: 4, 6, 8, and 10. Figure 8 data: Wild-type petunia plants were grown in conditions which limited axillary bud outgrowth (long days, crowded, sparing application of water and fertilizer) to maximize expression of strigolactone pathway genes. Samples were taken at four time points - 3, 5, 7, and 9 weeks post-germination. The samples were: fine lateral roots $(\mathrm{RL})$; the primary root immediately below the hypocotyl (up to $3 \mathrm{~cm}$ in length, RP); for the 3-week sample the entire stem (S); for the remaining time points $2 \mathrm{~cm}$ of stem above node 1 (SL) where branching generally occurs; $2 \mathrm{~cm}$ of stem above node eight (SM) where branching is generally suppressed; a young leaf (L) sample was taken from the 3-week-old plants; and a flower bud (FB) sample from the 9-week-old plants.

RNA was isolated using the RNeasy Plant Mini Kit (Qiagen) following the manufacturer's instructions. Some samples were additionally purified using a standard phenol: chloroform, ethanol precipitation method. Genomic DNA contamination was removed using Turbo DNase (Ambion), and the RNA quality tested using a Bioanalyzer 2100 (software version 2.5), before production of cDNA using Superscript III (Invitrogen) with an anchored $\mathrm{dT}_{23} \mathrm{~V}$ primer.

Quantitative RT-PCR was carried out for each target gene and three internal control genes Actin, EF-1a, and Histone 4 for each sample on a single plate using the Lightcycler 480 machine, 384well plates, and SYBR green I Master reagents (Roche). The primers used to amplify the previously described genes are listed in Snowden et al. (2005) and Drummond et al. (2009c). The primers for PhMAX1 are oM1-9/oM1-10, for PhMAX2A were oM2A9/oM2A-10, for PhMAX2B were oM2B-1/oM2B-2, and for CAB were oCAB-1/oCAB-2 (Table 1). The Cq values were calculated using the second derivative maximum method as implemented in the Lightcycler 480 software. PCR efficiencies were calculated using LinRegPCR (v11; Ruijter et al., 2009) for each reaction and averaged over each amplicon (Karlen et al., 2007), before the relative expression was calculated using the comparative cycle threshold method (Pfaffl, 2001), with normalization of data to the geometric average of the internal control genes (Vandesompele et al., 2002). Expression levels were then rescaled relative to the sample with the greatest expression for each gene in each qPCR experiment (where biological replicates are shown together expression levels were rescaled relative to the sample with the greatest expression in replicate one).

\section{STATISTICAL TESTS}

ANOVAs were performed for statistical analyses of phenotypic data using the GenStat statistical software package (12th Edn). Appropriate transformations were used to ensure that model assumptions were met where necessary. Mean separation tests were performed using Tukey's least significant difference (LSD) test at the $5 \%$ level of significance.

The data in Figure $\mathbf{8}$ was assessed in two ways. First the reproducibility between the biological replicates was quantified by determining the intra-class correlation coefficients (ICC) as calculated from a one way ANOVA model in SAS 9.2 (Lu and Nawar, 2009). Second, an analysis of the time dependent trends was conducted using Proc Mixed, the linear mixed model (LMM) procedure, in SAS 9.2. The S and SL sample types were combined for these tests. A model that included replicate and sample type as factors with day as a covariate was fitted separately to data from each gene. A sample type and day interaction was also included to allow for differing slopes over time for each sample type. The slopes 
and respective SE for each sample type were calculated by taking the appropriate linear combinations of the model coefficients. A $t$-test was then used to assess if there was evidence that each of these slopes differed from zero. $P$-values less than $0.05\left(^{*}\right)$ or less than $0.01\left(^{* *}\right)$ are indicated in Figure 8 and can be interpreted as evidence of an increasing (or decreasing) linear trend.

\section{SEQUENCE DATA}

The nucleotide sequences reported in this paper have been deposited in the GenBank database under the accessions HM117628 (PhMAX1), HM117629 (PhMAX2A), and HM117630 $(P h M A X 2 B)$. Table 1 lists the names and sequence of the DNA primers developed as a part of this research.

\section{RESULTS}

\section{PhMAX1 IS ORTHOLOGOUS TO MAX1 (CYP711A1)}

Degenerate primers designed to conserved regions of AtMAX1 were used to isolate a fragment of PhMAX1 from petunia genomic DNA by PCR. Using iPCR, this sequence was extended to a total of 4254 bp of genomic sequence that contained the putative petunia PhMAX1 gene (GenBank Accession: HM117628). A full-length cDNA clone of the gene was amplified from petunia cDNA, cloned, and sequenced to confirm intron-exon boundaries. Figure $2 \mathrm{~A}$ shows the gene structure for the putative petunia PhMAX1 locus.

The CYP711A family has expanded in some plant species, for example the rice genome contains five CYP711A genes (Nelson et al., 2004). To determine if this is the case in petunia, we investigated the copy number of PhMAX1 using Southern analysis. Probe 1 , made against a region of the gene likely to only detect CYP711A sub-family genes, detected one band of the expected size in each digest, suggesting that no closely related sequences exist in this genome (Figure 2B). However, Probe 2 made to a sequence conserved across a wider range of cytochrome P450 genes detected up to three bands in a single digest, suggesting that petunia does have a significant number of cytochrome $\mathrm{P} 450$ genes more distantly related to PhMAX1 (Figure 2C). Using the 454PetuniaDB sequence database ${ }^{1}$, we were unable to identify any sequence with sufficient similarity to suggest paralogy.

To determine the phylogenetic relationships between the putative petunia MAX1 and other similar proteins, the predicted protein sequence was used in BLAST searches against the Arabidopsis proteome. We identified a number of closely related sequences; as expected, all were cytochrome P450 monooxygenases. We selected 14 closely related $\left(E>4 \mathrm{e}^{-25}\right)$ proteins covering six families for further analysis. As shown in Figure 2D the protein from petunia is most similar to MAX1 (CYP711A1) and is $72 \%$ identical at the amino acid level. Together, these results suggest that PhMAX1 is likely to be a single copy gene that is orthologous to AtMAX1.

\section{PhMAX2A AND PhMAX2B ARE ORTHOLOGOUS TO MAX2}

Degenerate primers designed to conserved regions of AtMAX2 were used to isolate a fragment of $P h M A X 2 A$ from petunia genomic DNA by PCR. A series of PCR and PCR reactions were then performed to isolate $2329 \mathrm{bp}$ of genomic DNA sequence

\footnotetext{
${ }^{1}$ http://biosrv.cab.unina.it/454petuniadb/
}

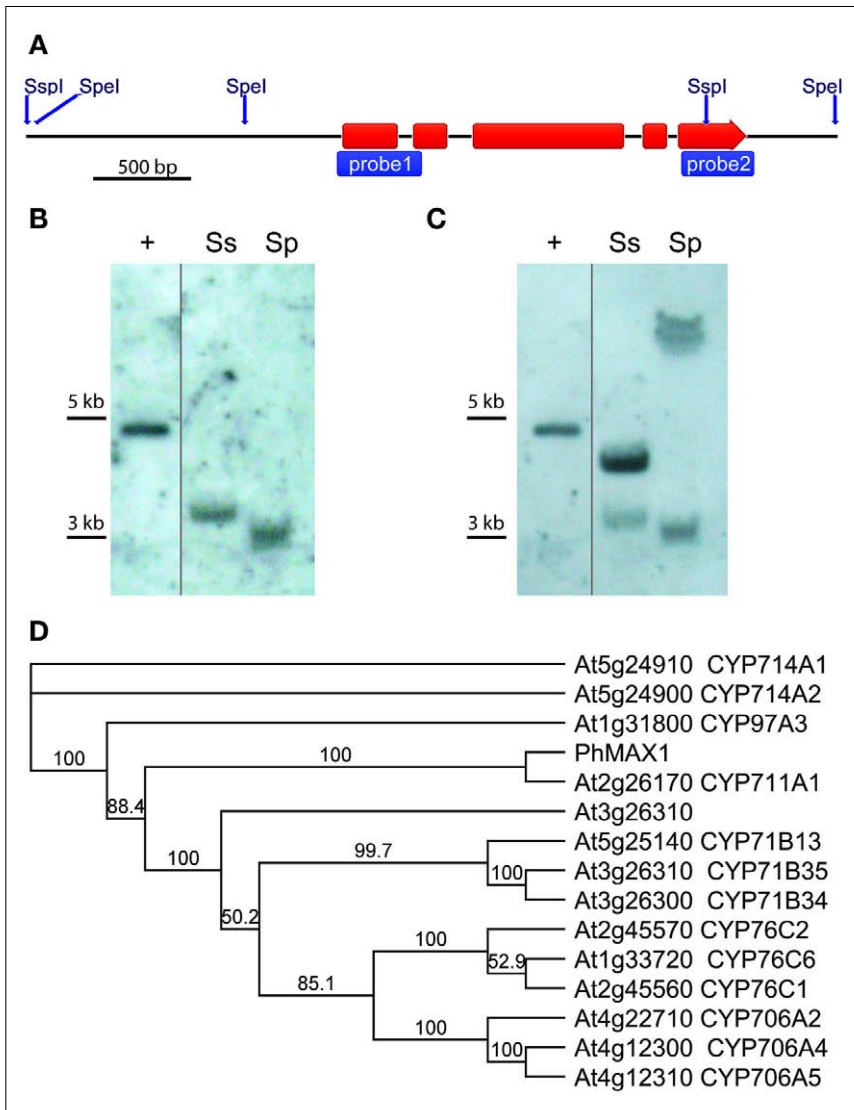

FIGURE 2 |The PhMAX1 gene. (A) Structure of the gene, exons are shown in red, probes and restriction enzymes used in the Southern analysis are shown in blue. (B,C) A petunia genomic DNA Southern blot probed with a fragment of PhMAX1 with either (B) high, probe 1, or (C) low, probe 2, variability amongst cytochrome $\mathrm{P} 450$ genes. The image shown in (B) is from a high stringency wash $\left(0.1 \times \mathrm{SSC}, 65^{\circ} \mathrm{C}\right)$, a prior medium stringency wash $\left(0.5 \times \mathrm{SSC}, 65^{\circ} \mathrm{C}\right)$ showed no additional bands. The image in (C) is from a medium stringency wash. The lanes are: +, positive control; Ss, Sspl digest; Sp, Spel digest. The line indicates where intervening lanes have been removed for clarity. (D) A maximum likelihood phylogeny showing the petunia MAX1 protein in relation to similar CYP450 proteins in Arabidopsis. Sequences have been labeled with their TAIR locus number and any CYP450 name associated with the sequence. CYP711A1 is MAX1. The tree is unrooted and the values indicated on branches are bootstrap percentages (out of 1000 replicates).

(GenBank Accession: HM117629). The transcript of PhMAX2A was confirmed by PCR amplifying and cloning a cDNA copy of the gene. The PhMAX2A gene consists of a single exon as shown in Figure 3B.

We investigated the copy number of MAX2 in petunia using Southern analysis. The probe detected single bands in the MfeI and EcoRI digests, but two bands in the digests using NcoI (Figure 3C), suggesting that there might be a closely related gene in petunia. Using the 454PetuniaDB sequence, we identified a second gene in petunia with sequence similarity to $M A X 2$. Using iPCR, we have cloned and sequenced DNA fragments covering $2660 \mathrm{bp}$ of genomic sequence at the PhMAX2B locus (GenBank Accession: HM117630). The two genes are $77 \%$ identical at the nucleotide level over the coding sequence and $78 \%$ identical at the protein 


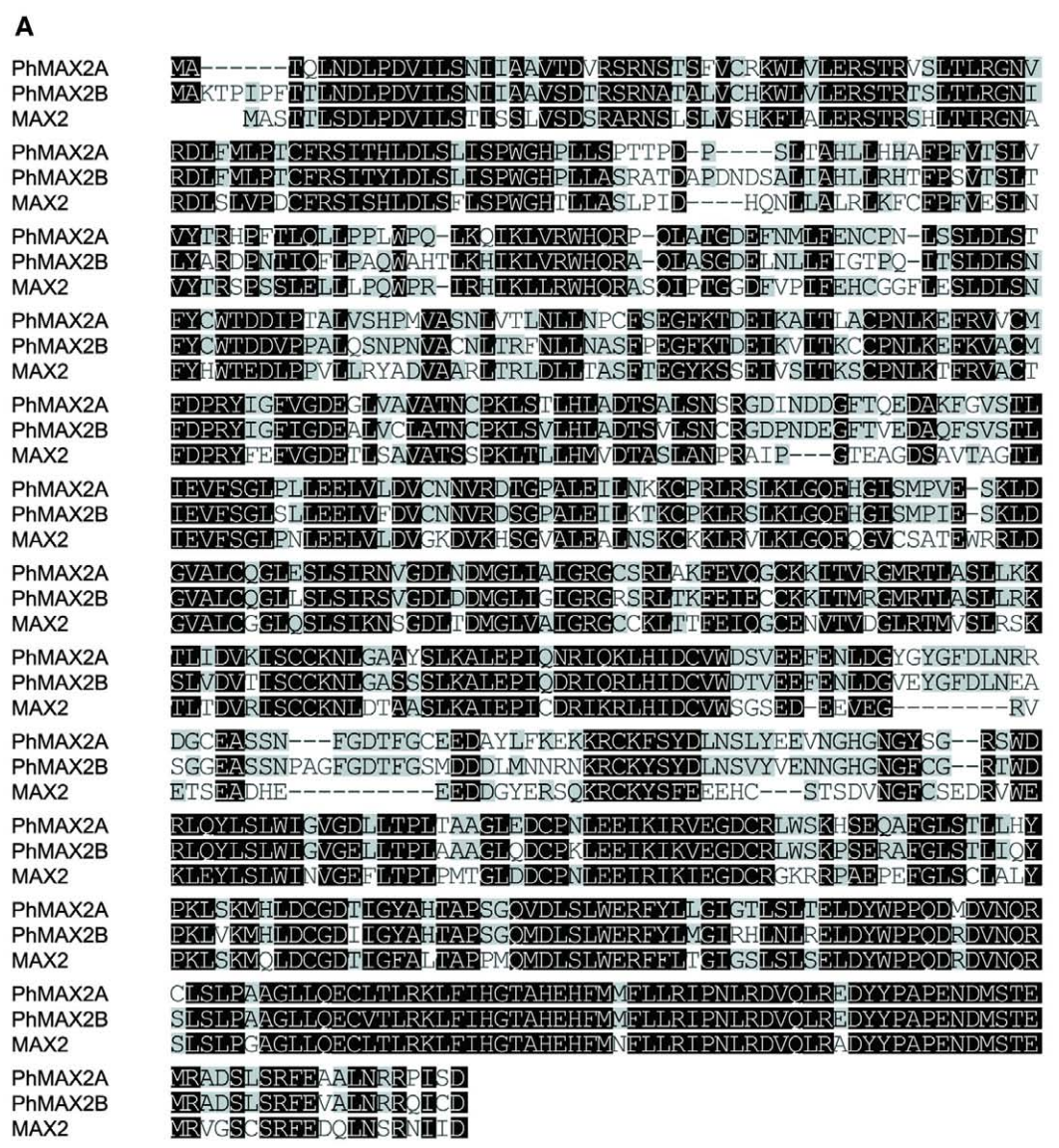

B

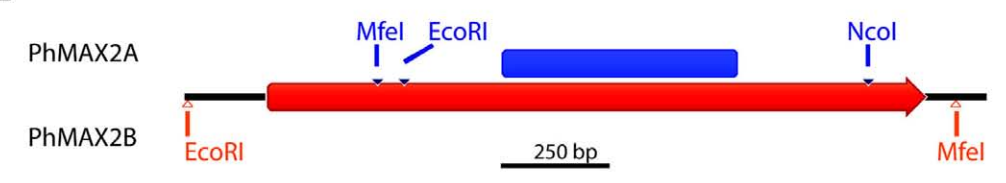

C

D
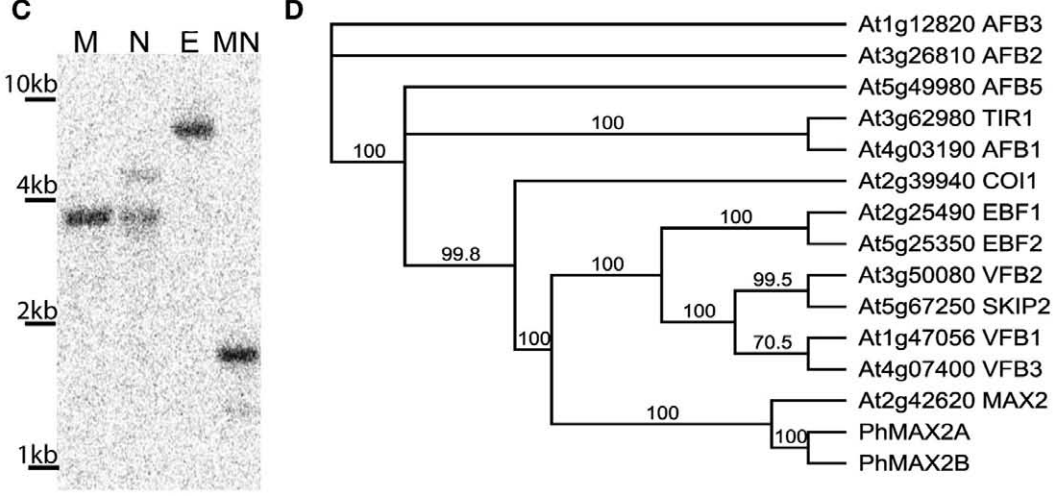

FIGURE 3 |The PhMAX2A and PhMAX2B genes. (A) An alignment of the MAX2, PhMAX2A, and PhMAX2B predicted proteins, sequences are shaded by similarity. (B) Structure of the PhMAX2 genes, the black line represents the DNA sequence, both genes consist of a single exon, the PhMAX2A exon (2127 bp) is shown in red. The PhMAX2B exon is $45 \mathrm{bp}$ larger. The restriction sites used in the Southern blot are shown above the sequence in blue for PhMAX2A and below the sequence in orange for PhMAX2B. The Southern blot probe, created from PhMAX2A, is shown above the sequence as a blue bar. (C) A petunia genomic DNA Southern blot probed with a fragment of PhMAX2A. The lanes are: M, Mfel; N, Ncol digest; E, EcoRI digest; MN, Mfel Ncol double digest. (D) A maximum likelihood phylogeny showing the PhMAX2A and PhMAX2B proteins in relation to the LRR7 F-Box proteins in Arabidopsis. Sequences have been given their TAIR locus number and any gene name associated with the sequence. The tree is unrooted and the values indicated on branches are bootstrap percentages over 1000 replicates. 
level. An alignment of the two petunia proteins and MAX2 from Arabidopsis is shown in Figure 3A. PhMAX2A is 60\% identical to MAX2 at the amino acid level and PhMAX2B is 59\% identical to MAX2.

The evolutionary relationships of the F-box super family have recently been examined by Xu et al. (2009). The MAX2 protein belongs to the LRR_7 family. In Arabidopsis there are 13 subfamilies in this group. When compared with the proteins from the LLR_7 group, the putative petunia MAX2 proteins are most similar to one another and form a monophyletic clade with MAX2 (Figure 3D).Taken together, these results suggest that PhMAX2A and $P h M A X 2 B$ are paralogous genes that are orthologous to AtMAX2.

Due to the similarity of the grafting results for the $\max 2$ and dad 2 mutants we investigated the possibility that the PhMAX2A or PhMAX2B genes could be DAD2. However, sequencing of these two genes in the dad 2 mutant did not uncover any differences in sequence to the gene in wild-type plants $(2.3$ and $2.6 \mathrm{~kb}$ was sequenced respectively for PhMAX2A and PhMAX2B covering the regions represented in the GenBank Accessions HM117629 and HM117630).

\section{STEADY STATE mRNA LEVELS IN MATURE WILD-TYPE AND DAD MUTANT PETUNIA}

It has been suggested that the differences between species are most frequently derived from changes in gene expression, timing, and localization rather than changes in protein function (King and Wilson, 1975). To investigate whether the morphological differences between petunia and Arabidopsis might be explained by changes in the expression of the PhMAX1, PhMAX2A, or PhMAX2B genes, we used qPCR to examine the steady state mRNA levels of these genes in mature wild-type and dad mutant petunia.

Publically available microarray data suggest that AtMAX1 is expressed throughout the plant ${ }^{2}$. This was refined by Booker et al. (2005) using a promoter GUS reporter system to show that the expression is restricted to vascular bundles. We detected PhMAX1 transcripts in all seven organs of the wild-type petunia we tested and found the greatest abundance in the low stem samples, with the difference between the highest and lowest abundance being a single order of magnitude; a biological replicate showed a similar trend (Figure 4A).

The expression of MAX2 orthologs has been investigated in rice, pea, sorghum, and Arabidopsis. In all four plants gene transcripts were detected in all the organs tested. In rice and Arabidopsis there was little sign of variation in transcript abundance with respect to organ type (Shen et al., 2007; Stirnberg et al., 2007; Mashiguchi et al., 2009). However, in pea, mRNA levels were at least 3.5 times greater in stipules than any other tested material (Johnson et al., 2006), and in sorghum mRNA levels were greatest in roots (Kebrom et al., 2010). In petunia we detected PhMAX2A and $P h M A X 2 B$ transcripts in all seven samples tested. The pattern of transcript levels varied both between the genes and between the biological replicates (Figures 4B,C). PhMAX2B shows variability between replicates in root, leaf, and shoot apex, whereas

${ }^{2}$ http://arabidopsis-p450.biotec.uiuc.edu/microarray.shtml

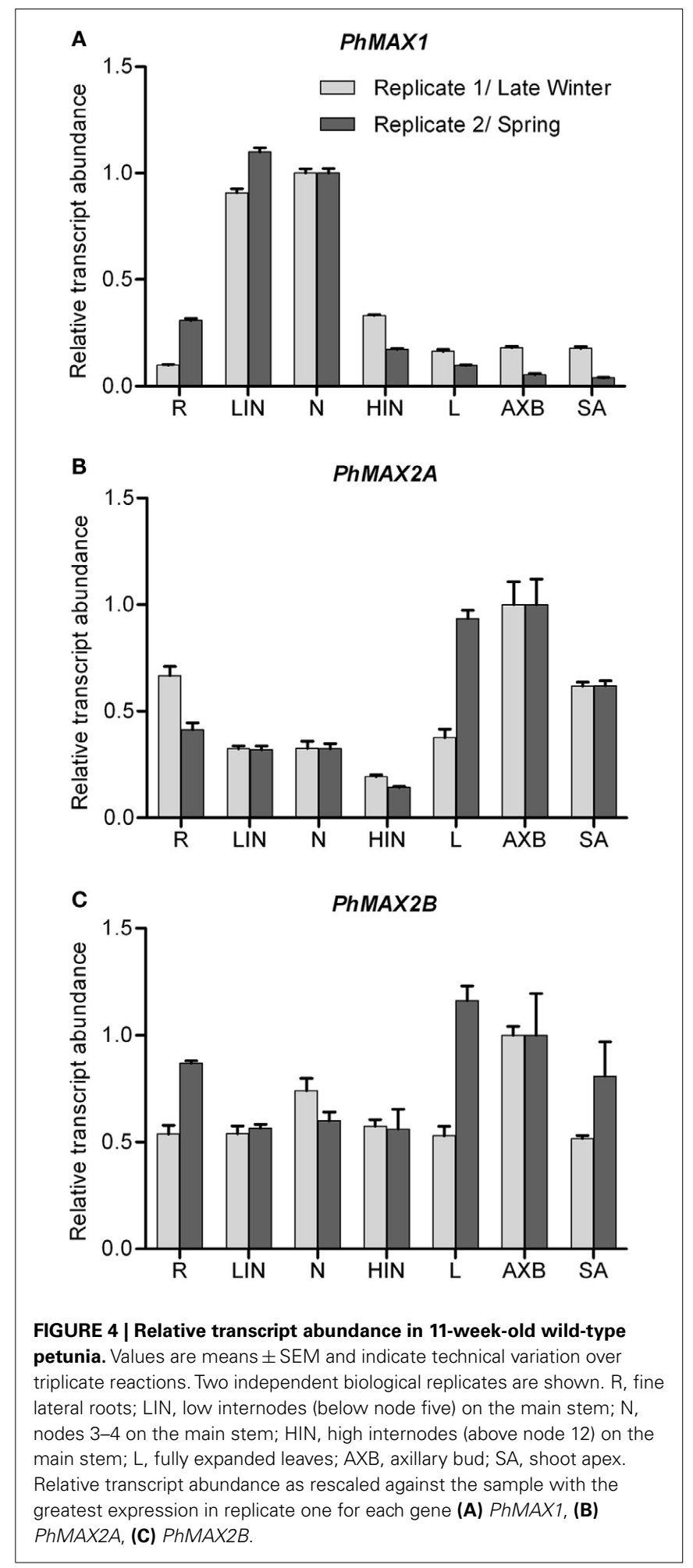

PhMAX2A shows variability only in root and leaf samples. Some consistent similarities are also apparent - the abundance of both genes' transcripts in leaves is greater in replicate two than in replicate one, and the abundance of both genes' transcripts is greatest in axillary buds (and leaves in replicate two), having approximately 
twofold greater abundance than most other organs. With regard to absolute transcript levels, our analysis suggests that the PhMAX2A and $P h M A X 2 B$ transcripts are present at similar levels to each other (data not shown).

No changes in the transcript abundance of MAX2 (or the orthologous gene $D 3$ in rice) were detected in any of the branching mutants tested (Arite et al., 2007; Stirnberg et al., 2007; Mashiguchi et al., 2009). The expression of the PhMAX1, PhMAX2A, and $P h M A X 2 B$ genes was not eliminated in any of the petunia dad mutants, including dad2 (Figure 5). However, PhMAX2A and $P h M A X 2 B$ transcript abundance was reduced in $\mathrm{dad} 1$ and $d a d 2$ axillary buds (Figures 5B,C), but not in $\mathrm{dad} 3$ axillary buds, which may be because the $d a d 3$ mutant phenotype is less severe than that of $d a d 1$ or $d a d 2$ (Snowden and Napoli, 2003). PhMAX1 transcript abundance may be slightly elevated in stem samples in all three dad mutants (Figure 5A). The small differences in mRNA levels observed may be indirect effects from altered plant morphology in the dad mutants.

\section{PhMAX2A mRNA LEVELS ARE CORRELATED WITH LEAF AGE/POSITION}

The variability in leaf expression seen above and the knowledge that the MAX2 gene of Arabidopsis is involved in leaf senescence led us to hypothesize that the MAX2 genes of petunia might show altered transcription over leaf development.

A series of leaves were collected from wild-type petunia plants that represented a progression of leaf ages/positions (Figure 6D). As a molecular measure of leaf age we used the Chlorophyll AB binding protein transcript as a well described marker; younger leaves have greater abundance of the transcript (Hensel et al., 1993). The abundance of the CAB transcript was negatively correlated with leaf age as expected (Figure 6A). The abundance of the PhMAX2A and PhMAX2B transcripts were measured in the same samples. PhMAX2A transcript levels (Figure 6B) were highest in older leaves, decreasing in progressively younger, more apical leaves. PhMAX2B mRNA levels did not show any consistent changes, remaining largely unchanged across the samples (Figure 6C).

\section{THE PhMAX1 AND PhMAX2A PROTEINS FUNCTION IN THE CONTROL OF BRANCHING}

The different transcript abundance patterns of the PhMAX2A and $P h M A X 2 B$ genes suggested that the function of the genes may have diverged, perhaps separating the control of senescence from the control of branching. To determine if the PhMAX2A gene still controls branching in petunia we attempted to remove this gene's transcripts by RNAi knockdown. In tandem with the PhMAX2A experiment we attempted to knockdown PhMAX1 expression as the function of MAX1-like genes has only been described in Arabidopsis. Wild-type petunia were transformed with Cauliflower mosaic virus $35 \mathrm{~S}$ (35S) promoter-expressed RNAi hairpin knockout constructs targeting either the PhMAX1 or PhMAX2A genes. Plants carrying the transgenes were characterized for branching phenotypes and for mRNA levels of the PhMAX1 or PhMAX2A gene as appropriate. In the best case, $P h M A X 1$ transcript abundance, as measured by qPCR, was lowered to $20 \%$ of the control and PhMAX2A transcript abundance lowered to $40 \%$ of the control (Figure A1 in Appendix). Branching was increased in these

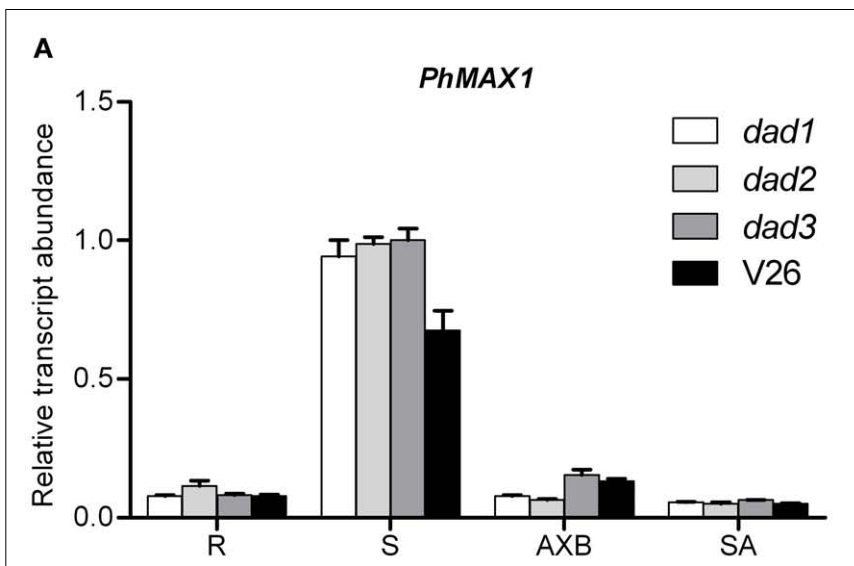

B

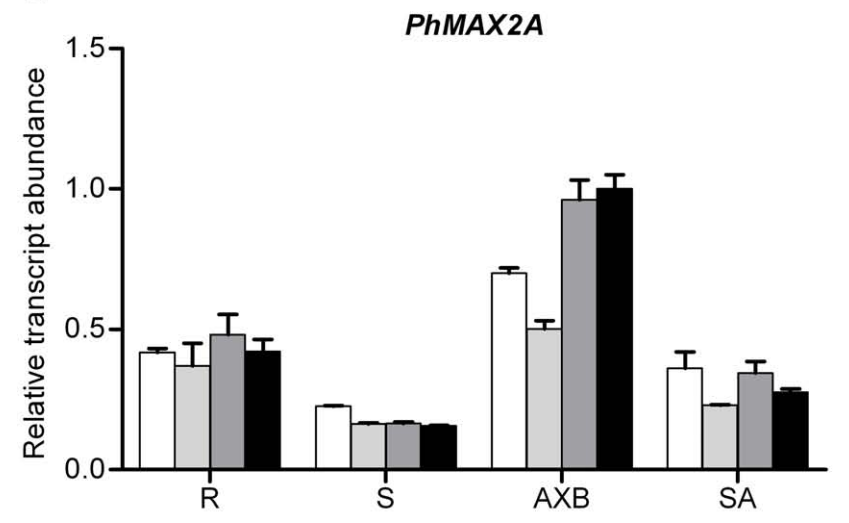

C

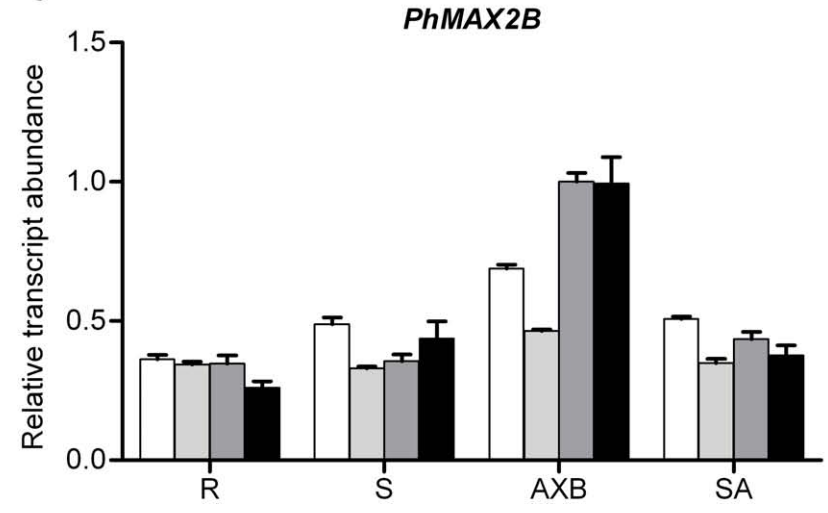

FIGURE 5 | Relative transcript abundance in 8-week-old wild-type and dad mutant petunia. Values are means \pm SEM and indicate technical variation over triplicate reactions. $R$, fine roots; $S, 2 \mathrm{~cm}$ of stem above the cotyledons (nodes and internodes); AXB, axillary bud; $S A$, shoot apex. Relative transcript abundance as rescaled against the sample with the greatest expression for each gene (A) PhMAX1, (B) PhMAX2A, (C) PhMAX2B.

lines and height decreased but the effect was subtle, generally not statistically significant, and was poorly correlated with the change in mRNA levels (Figure A1 in Appendix).

As an alternate method to test whether these petunia genes could still function in the control of branching we stably 


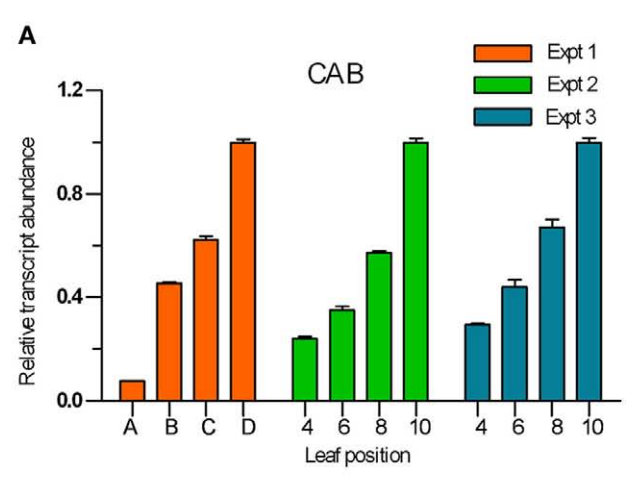

B

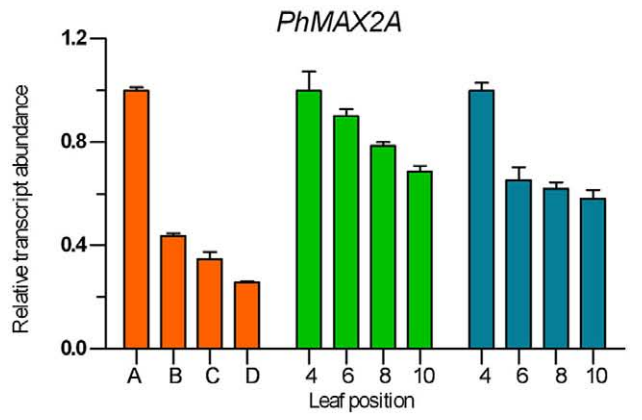

C

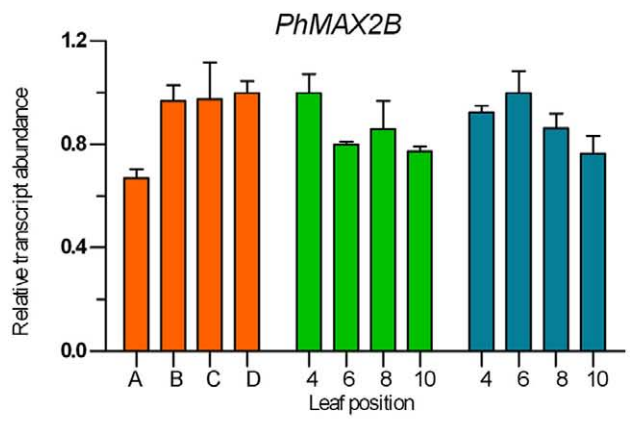

D
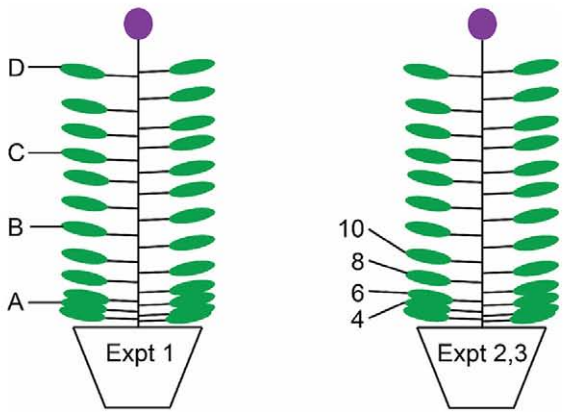

FIGURE 6 | PhMAX2A and PhMAX2B transcript abundance in petunia leaves. In the first experiment (Experiment 1) leaves were sampled from four positions on 8-week-old plants. Position A is $1 \mathrm{~cm}$ above the cotyledons, position $D$ is two nodes below the first flower, positions $B$ and $\mathrm{C}$ are equally spaced between these samples. In the second and third experiments (Experiments 2 and 3) leaves were sampled at nodes 4, 6, 8, and 10 on 9-week-old plants. Relative transcript abundance was rescaled against the sample with the greatest expression for each gene in each experiment (A) CAB, (B) PhMAX2A, (C) PhMAX2B. Values are means \pm SEM and indicate technical variation over triplicate reactions. (D) Diagram showing the sampling methodology, for simplicity branches and spiral phyllotaxy of leaves are not shown.
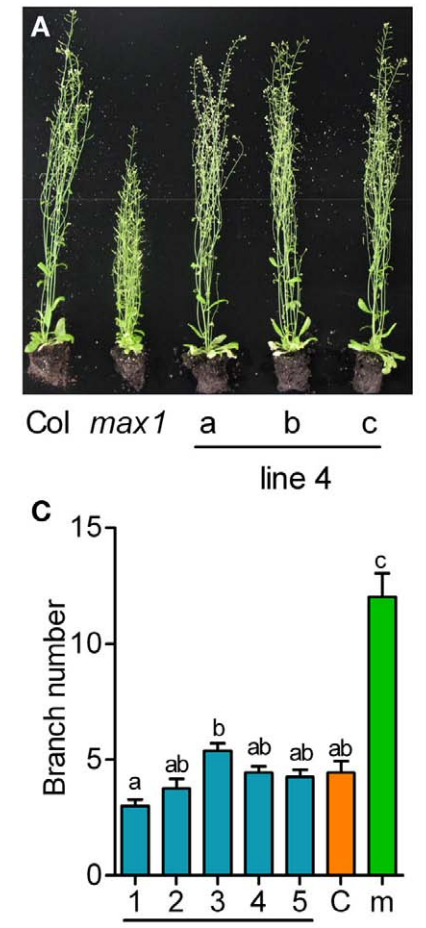

35S:PhMAX1 in $\max 1$

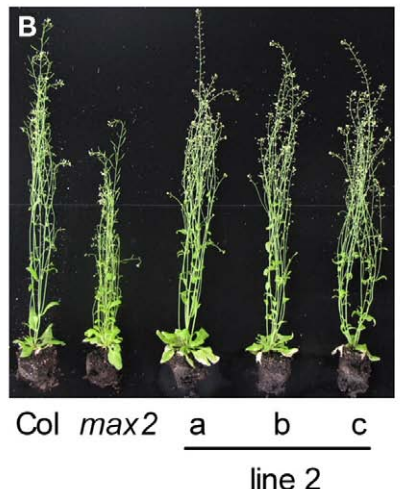

D 20

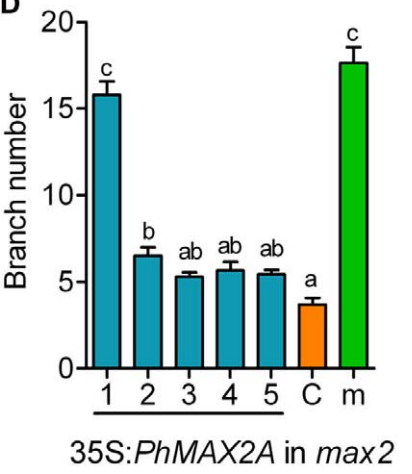

FIGURE 7 | Complementation of max mutants by petunia genes. (A) Representative late flowering stage (8-week-old) Arabidopsis plants are shown for the genotypes: "Columbia" (Col) wild-type, max1 mutant, and the fourth of the T3 transgenic max1/35S: PhMAX1 lines (a-c). (B) Col, max2, and the second of the T3 max2/35S: PhMAX2A lines (a-c). (C,D) Graphs showing the mean branch number ( \pm SEM, $n \geq 6$ ) of transgenic, wild-type, and mutant Arabidopsis. Values with the same lowercase identifier are not significantly different $(P=0.05)$. (C) Five independent T3 lines of max1/35S: PhMAX1 compared with Col, $\mathrm{C}$, and max1, $\mathrm{m}$, plants. (D) Five independent T3 lines of max2/35S: PhMAX2A compared with Col, $\mathrm{C}$, and max2, $\mathrm{m}$, plants.

transformed the Arabidopsis max1 mutant with a full-length cDNA copy of PhMAX1, and the Arabidopsis max2 mutant with a fulllength cDNA copy of PhMAX2A. The PhMAX1 and PhMAX2A genes were able to complement the equivalent max mutant in Arabidopsis (Figures 7A,B). In five T3 homozygous lines the PhMAX1 gene was able to decrease the branch number of $\max 1$ plants to wild-type (Figure 7C). In three of five lines PhMAX2A was able to revert $\max 2$ to wild-type (Figure 7D). These results show that $P h M A X 2 A$ has retained the ability to function in the control of branching.

\section{CONTROLLING BRANCH OUTGROWTH DURING VEGETATIVE DEVELOPMENT}

Developmental changes in branching may be due to changes in abundance of strigolactones or sensitivity to the strigolactone signal. Some of these changes could be regulated at the transcriptional level. If strigolactone levels increase with plant age then the biosynthetic genes CCD7, CCD8, and MAX1 would be expected to increase in expression over time. As MAX2 is involved 
in strigolactone signal transduction then expression of MAX2 may be altered in stem regions that are more sensitive to branch inhibition. To test this hypothesis, we investigated whether the transcript abundance of the PhMAX1, PhMAX2A, PhMAX2B, PhCCD7, and $P h C C D 8$ genes increased during development.

The transcript abundance of PhMAX1 increased during the development series (see Figure 8A for photographs of representative plants sampled) in the primary root (RP) and stem (S/SL and SM) samples, and there was good correlation, $\mathrm{ICC}=0.97$, between the replicates (Figure 8B). Similar trends were seen in the abundance of the PhCCD8 transcript (Figure $8 \mathbf{F}$ ), again with good correlation between replicates $(\mathrm{ICC}=0.82)$. However, in the low stem (S/SL) sample type the correlation was nonsignificant due to the variation between the replicates in this tissue type. An increase in the amount of PhMAX2A transcript over time was seen in the mid-stem (SM) samples, whilst the transcript levels in the remaining samples were largely unaltered during development (Figure 8C). The amount of PhMAX2B transcript increased during development in the low stem (S/SL) sample type but was unchanged across the remaining samples (Figure 8D). The ICC values for PhMAX2A and PhMAX2B samples were 0.74 and 0.69 respectively. The mRNA levels of PhCCD7
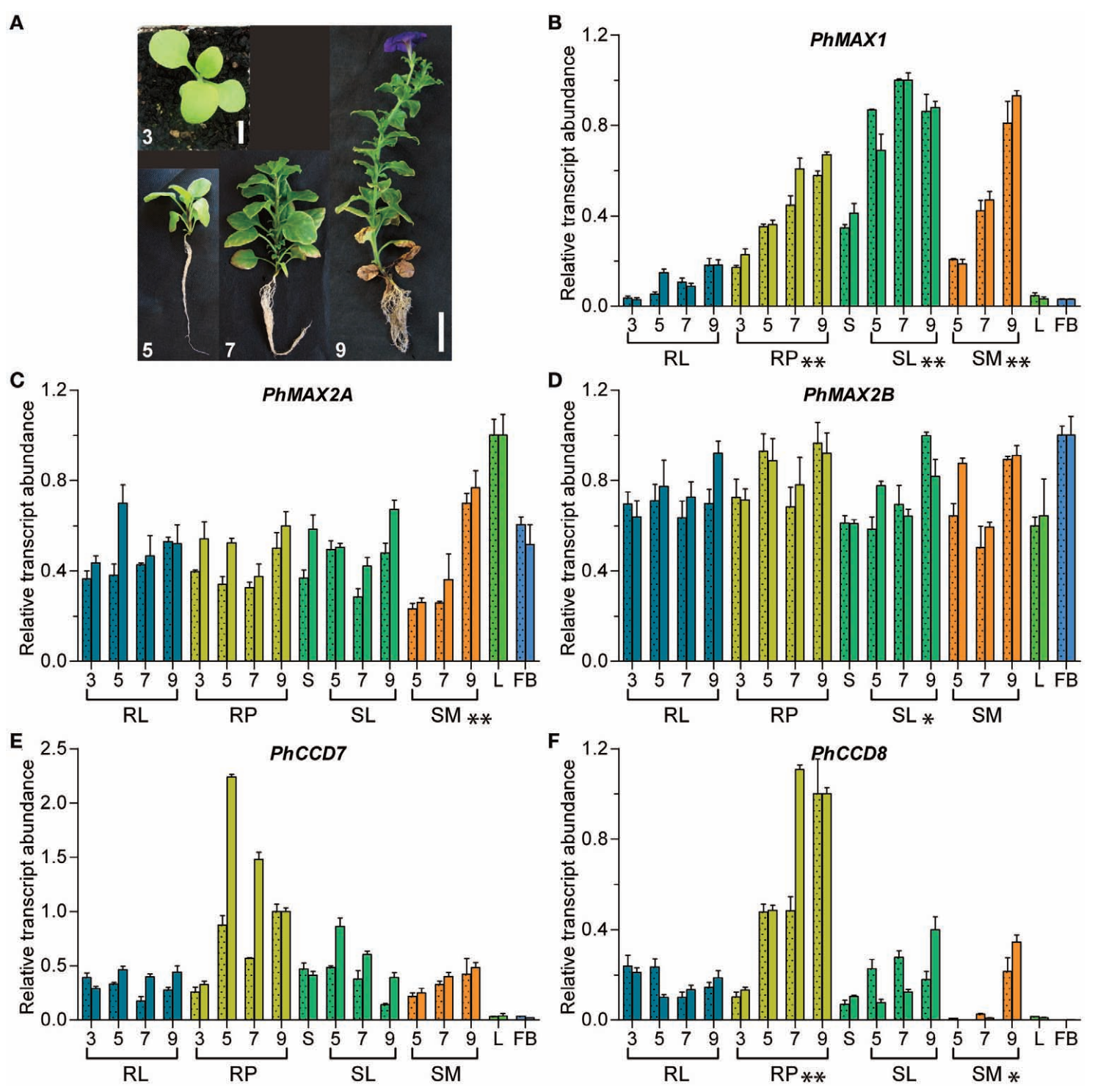

FIGURE 8 |A developmental series of petunia. (A) Petunia plants at: 3 weeks old (scale bar $2 \mathrm{~cm}$ ), 5, 7, and 9 weeks old (scale bar $5 \mathrm{~cm}$ ). (B-F) Relative transcript abundance. Values are means \pm SEM and indicate technical variation over triplicate reactions. Two independent biological replicates are shown. The values on the $x$-axis indicate number of weeks post-germination. Samples are $\mathrm{RL}$, fine lateral roots; $\mathrm{RP}, 2 \mathrm{~cm}$ of the primary root immediately below the hypocotyl; $S$ entire stem; SL, $2 \mathrm{~cm}$ of stem above node 1; SM,

$2 \mathrm{~cm}$ of stem above node eight; L, leaves 2-4; FB, flower buds less than $5 \mathrm{~mm}$ in length. Changes in transcript abundance for each sample type over time were significant at $P<0.01\left({ }^{*}\right)$ or $P<0.05\left({ }^{*}\right)$ as indicated (the $\mathrm{S}$ sample was grouped with the other SL samples for this analysis). Relative transcript abundance as rescaled against the sample with the greatest expression in replicate one for each gene (B) PhMAX1, (C) PhMAX2A, (D) PhMAX2B, (E) PhCCD7, (F) PhCCD8. 
displayed greater variability between replicates than the other genes $(\mathrm{ICC}=0.54)$, and no indication of statistically significant time dependent changes were detected (Figure 8E).

\section{DISCUSSION}

We have cloned three genes from petunia; one is orthologous to MAX1 (CYP711A1) and the other two are orthologous to MAX2. All four MAX genes in Arabidopsis now have orthologs identified in petunia. We have shown that a number of genes implicated in strigolactone production and reception have altered mRNA levels during plant development. PhMAX2A mRNA levels are correlated with leaf age or position in petunia, yet this gene was able to complement the increased branching phenotype of max2 in Arabidopsis, suggesting MAX2 and PhMAX2A have the same biochemical function.

Southern analysis suggested that there might be homologous sequences to the PhMAX1 gene in the petunia genome (Figure 2C). However, these are likely to be more distantly related cytochrome P450 genes that are not orthologous to AtMAX1. In addition, searches of sequence databases have not revealed any additional petunia candidate genes with a high degree of similarity. During the cloning of the PhMAX1 gene from petunia we used degenerate primer PCR and iPCR, both of which frequently yield offtarget sequence of closely related genes, but the only sequences we obtained belonged to PhMAX1. Taken together, these results suggest that PhMAX1 is a single copy gene in petunia.

The two MAX2 genes of petunia are candidates for the $D A D 2$ gene. Aside from similar phenotypes (decreased height and increased branching) the max 2 and $d a d 2$ mutants share the feature that mutant scions cannot be reverted to wild-type by grafting to wild-type rootstocks (Booker et al., 2005; Simons et al., 2007). Additionally, combining either the max 2 or dad 2 mutants with the $c c d 7$ or $c c d 8$ mutants did not produce additive double mutant phenotypes also indicating that both genes act in the same pathway (Booker et al., 2005; Simons et al., 2007). We sequenced the genomic loci containing the PhMAX2A and PhMAX2B genes, and have cloned wild-type cDNA copies of each. No alterations to the sequence were detected between the genomic loci from wild-type or dad 2 mutant petunias. Additionally we show that the mRNA levels for the PhMAX2A and PhMAX2B genes occur in the dad 2 mutant in a pattern similar to that seen for dad1 (Figure 5). This demonstrates that the expression of these genes has not been eliminated, and suggests that their regulation has not been grossly perturbed in the $d a d 2$ mutant. These results lead us to conclude that it is unlikely that either PhMAX2A or $P h M A X 2 B$ is the DAD2 gene. However, there remains the possibility that a cis-regulatory polymorphism or epigenetic modification leading to more subtle changes in the timing or localization of PhMAX2A or PhMAX2B expression could account for the dad 2 mutant phenotype.

Wild-type petunias produce a limited number of branches from near the base of the plant during vegetative growth. The dad1 and $d a d 2$ mutants have an increased branching phenotype such that in many environmental conditions all of the axillary buds on the main stem become branches. The dad3 mutant has a branching phenotype intermediate between wild-type and the other dad mutants. As such all axillary buds on the main stems of dad1 and dad2 plants are actively growing whilst those on wild-type and dad 3 plants are a mixture of dormant and growing. Our data on the expression of PhMAX1, PhMAX2A, and PhMAX2B in the axillary buds of petunias (Figure 5) suggests that expression of these genes may be correlated with dormancy, the expression of the three genes is low in dad1 and dad2 axillary buds but high in wild-type and dad3.

In petunia there are two copies of the MAX2 gene. This sort of duplication has the potential to allow the unconstrained mutation of one copy; however our observations suggest in this case that both copies are being maintained in a functional state. Although a large number of nucleotide differences are apparent, the petunia proteins produced are more similar to one another than either is to the Arabidopsis MAX2 protein. None of the changes has led to either petunia copy becoming obviously non-functional as most changes are silent or conservative at the protein level and none are non-sense mutations. The PhMAX2A gene has retained its ability to function in the control of branching, as we have demonstrated the complementation of $\max 2$ by this gene, at least when expressed from the $35 \mathrm{~S}$ promoter (Figure 7). It is possible that PhMAX2A or PhMAX2B are functionally redundant, however, given that we were unable to produce plants with less than $40 \%$ the normal PhMAX2A mRNA levels and that the genes have different transcript abundance profiles (Figures 4-6 and 8 ) it seems likely that the genes do not have entirely redundant functions. Isolation and characterization of single and double mutants for the PhMAX2A and PhMAX2B genes might uncover which functions, if any, are shared by or are unique to these genes.

In Arabidopsis, MAX2 is involved in at least three developmental processes; axillary branching, leaf senescence, and photomorphogenesis of seedlings (Woo et al., 2001; Stirnberg et al., 2002; Shen et al., 2007). The involvement of this gene in three developmental processes makes it a good candidate for evolving under the mosaic pleiotropy principle (Carroll, 2008), with evolutionary change resulting from changes in expression rather than protein function. By contrast the evolution of the petunia genes is not constrained by having multiple functions dependent on a single MAX2 protein and it is possible that protein function is also diverging. Our evidence suggests that the transcript abundance of PhMAX2A increases with leaf age or position (while that of $P h M A X 2 B$ is not), and could be hypothesized to be increasing the sensitivity of older leaves to senescence inducing signals. However the gene is still capable of functioning in the control of branching in Arabidopsis. In future work an examination of any differentiation in the function of the promoters or proteins of the AtMAX2, $P h M A X 2 A$, and $P h M A X 2 B$ genes or orthologs from other species that differ in $M A X 2$ copy number may contribute to evolutionary theory in this area.

Petunia typically produces a small number of branches from adjacent basal axillary nodes. New basal branches are initiated during vegetative development and this process is generally complete before flowering commences. One hypothesis that may explain the inhibition of axillary meristems above this basal branching is that there is a molecular mechanism in petunia that produces more of a branch inhibiting signal as development progresses or increases sensitivity to such a signal. Two genes proposed to be involved in 
the production of strigolactone ( $P h M A X 1$ and $P h C C D 8$; Figure 8) have increased mRNA levels during development, suggesting that strigolactone levels also increase during development. In kiwifruit, a woody perennial plant, $C C D 8$ mRNA levels have also been shown to vary during the growing season (Ledger et al., 2010). The mRNA levels of PhMAX2A (Figure 8), also increase during development, but only in the stem within a zone that in wild-type petunia only rarely produces branches. This suggests the possibility of increased sensitivity to a branching inhibitor in this region. Together, these changes may account for some of the differences in branching that occur in different zones of the stem of the plant (Snowden and Napoli, 2003), or at different times during plant growth. It would be valuable to obtain further resolution of the regulation of this pathway, by determining which cells within the plant are expressing these genes and extending this work to understanding what regulation occurs at the protein level. To that end, an important goal is to understand the signal transduction pathway for strigolactones. In the future it will be important to demonstrate the presence of the strigolactone molecule itself in the stems of plants and whether this level is somehow altered during development.

\section{REFERENCES}

Akiyama, K., Matsuzaki, K.-I., and Hayashi, H. (2005). Plant sesquiterpenes induce hyphal branching in arbuscular mycorrhizal fungi. Nature 435, 824-827.

Arite, T., Iwata, H., Ohshima, K., Maekawa, M., Nakajima, M., Kojima, M., Sakakibara, H., and Kyozuka, J. (2007). DWARF10, an RMS1/MAX4/DAD1 ortholog, controls lateral bud outgrowth in rice. Plant J. 51, 1019-1029.

Bell, A. (1991). Plant Form: An Illustrated Guide to Flowering Plant Morphology. Oxford: Oxford University Press.

Blixt, S. (1976). Linkage studies in Pisum. XV. Establishing the RMSgene and the linkage of RMS and FAS in chromosome 3. Agric. Hortic. Genet. 34, 83-87.

Booker, J., Auldridge, M., Wills, S., Mccarty, D., Klee, H., and Leyser, O. (2004). MAX3/CCD7 is a carotenoid cleavage dioxygenase required for the synthesis of a novel plant signaling molecule. Curr. Biol. 14, 1232-1238.

Booker, J., Sieberer, T., Wright, W., Williamson, L., Willett, B., Stirnberg, P., Turnbull, C., Srinivasan, M., Goddard, P., and Leyser, O. (2005). MAX1 encodes a cytochrome P450 family member that acts downstream of MAX3/4 to produce a carotenoid-derived branchinhibiting hormone. Dev. Cell 8, 443-449.

Brunaud, A., Bognon, F., and Cornu, A. (1977). Analyse du port chez 307-327.

Carroll, S. B. (2008). Evo-devo and an expanding evolutionary synthesis: a genetic theory of morphological evolution. Cell 134, 25-36.

Clough, S. J., and Bent, A. F. (1988). Floral dip: a simplified method for Agrobacterium-mediated transformation of Arabidopsis thaliana. Plant J. 16, 735-743. Wall, M. E., and Egley, G. H. (1966). Germination of witchweed (Striga lutea Lour.): isolation and properties of a potent stimulant. Science 154, 1189-1190.

Drummond, A., Ashton, B., Cheung, M., Heled, J., Kearse, M., Moir, R., Stones-Havas, S., Thierer, T., and Wilson, A. (2009a). Geneious v4.7. Available at: www.geneious.com

Drummond, R. S. M., Ledger, S. E., Simons, J. L., Janssen, B. J., and Snowden, K. C. (2009b). "Vegetative branching in petunia," in Petunia: Evolutionary, Developmental and Physiological Genetics, eds T. Gerats and J. Strommer (New York: Springer), 157-178.

Drummond, R. S. M., MartinezSanchez, N. M., Janssen, B. J., Templeton, K. R., Simons, J. L., Quinn, B. D., Karunairetnam, S., and Snowden, K. C. (2009c). Petunia hybrida CAROTENOID CLEAVAGE DIOXYGENASE7 is involved in the production of negative and positive branching signals in petunia. Plant Physiol. 151, 1867-1877.

Gleave, A. P. (1992). A versatile binary vector system with a T-DNA des Petunia. Acta Bot. Gall. 124,

Cook, C. E., Whichard, L. P., Turner, B.,

An interesting possibility is that the strigolactone pathway genes in other plant species might show quite different expression patterns during development resulting in different architectures. Considering the strigolactone signaling pathway with respect to both ontogeny and environmental inputs will yield information about how plant architecture has diversified between species.

\section{ACKNOWLEDGMENTS}

The authors would like to thank S. Karunairetnam for assistance in producing the overexpression and RNAi constructs, M. Wohlers, S. Y. Jia, and N. deSilva for assistance with statistics, B. J. Janssen and S. E. Ledger for assistance with data collection and useful discussion, R. Espley and R. MacDiarmid for critical reading of the manuscript and O. Leyser for the donation of max1 and max 2 seeds. We would also like to thank M. Pezzotti, D. Clark, and T. Gerats for allowing us access to the 454PetuniaDB. This work was supported by the Foundation for Research, Science, and Technology, New Zealand (contract numbers C10 × 0404 and $\mathrm{C} 10 \times 0816)$. Hester Sheehan was partially supported by a tertiary fees bursary from Horticulture New Zealand.

organisational structure conducive to efficient integration of cloned DNA into the plant genome. Plant Mol. Biol. 20, 1203-1207.

Gomez-Roldan, V., Fermas, S., Brewer, P. B., Puech-Pages, V., Dun, E. A., Pillot, J.-P., Letisse, F., Matusova, R., Danoun, S., Portais, J.-C., Bouwmeester, H., Becard, G., Beveridge, C. A., Rameau, C., and Rochange, S. F. (2008). Strigolactone inhibition of shoot branching. Nature 455, 189-194.

Guindon, S., and Gascuel, O. (2003). A simple, fast, and accurate algorithm to estimate large phylogenies by maximum likelihood. Syst. Biol. 52, 696-704.

Hanada, K. (1993). “Tillers," in Science of the Rice Plant: Volume One Morphology, eds T. Matsuo and K. Hoshikawa (Tokyo: Food and Agriculture Policy Research Center), 222-229.

Hempel, F. D., and Feldman, L. J. (1994). Bidirectional inflorescence development in Arabidopsis thaliana acropetal initiation of flowers and basipetal initiation of paraclades. Planta 192, 276-286.

Hensel, L. L., Grbic, V., Baumgarten, D. A., and Bleecker, A. B. (1993). Developmental and age-related processes that influence the longevity and senescence of photosynthetic tissues in Arabidopsis. Plant Cell 5, 553-564.

Ishikawa, S., Maekawa, M., Arite, T., Onishi, K., Takamure, I., and Kyozuka, J. (2005). Suppression of tiller bud activity in tillering dwarf mutants of rice. Plant Cell Physiol. 46, 79-86.
Johnson, X., Brcich, T., Dun, E. A., Goussot, M., Haurogné, K., Beveridge, C. A., and Rameau, C. (2006). Branching genes are conserved across species. Genes controlling a novel signal in pea are coregulated by other long-distance signals. Plant Physiol. 142, 1014-1026.

Jorgensen, R. A., Cluster, P. D., English, J., Que, Q., and Napoli, C. A. (1996). Chalcone synthase cosuppression phenotypes in petunia flowers: comparison of sense vs. antisense constructs and single-copy vs. complex T-DNA sequences. Plant Mol. Biol. 31, 957-973.

Karlen, Y., Mcnair, A., Perseguers, S., Mazza, C., and Mermod, N. (2007). Statistical significance of quantitative PCR. BMC Bioinformatics 8, 131. doi:10.1186/1471-2105-8-131

Kebrom, T., Brutnell, T., and Finlayson, S. (2010). Suppression of sorghum axillary bud outgrowth by shade, phyB and defoliation signalling pathways. Plant Cell Environ. 33, 48-58.

King, M., and Wilson, A. (1975). Evolution at two levels in humans and chimpanzees. Science 188, 107-116.

Ledger, S. E., Janssen, B. J., Karunairetnam, S., Wang, T., and Snowden, K. C. (2010). Modified CAROTENOID CLEAVAGE DIOXYGENASE8 expression correlates with altered branching in kiwifruit (Actinidia chinensis). New Phytol. 188, 803-813.

Lim, P. O., Kim, H. J., and Gil Nam, H. (2007). Leaf senescence. Annu. Rev. Plant Biol. 58, 115-136. 
Lu, L., and Nawar, S. (2009). Reliability Analysis: Calculate and Compare Intraclass Correlation Coefficients (ICC) in SAS. Available at: www.nesug.org/proceedings/nesug 07/sa/sa13.pdf [accessed December 21, 2011].

Mashiguchi, K., Sasaki, E., Shimada, Y., Nagae, M., Ueno, K., Nakano, T., Yoneyama, K., Suzuki, Y., and Asami, T. (2009). Feedback-regulation of strigolactone biosynthetic genes and strigolactone-regulated genes in Arabidopsis. Biosci. Biotechnol. Biochem. 73, 2460-2465.

Matusova, R., Rani, K., Verstappen, F. W. A., Franssen, M. C. R., Beale, M. H., and Bouwmeester, H. J. (2005). The strigolactone germination stimulants of the plant-parasitic Striga and Orobanche spp. are derived from the carotenoid pathway. Plant Physiol. 139, 920-934.

Napoli, C. A., and Ruehle, J. (1996). New mutations affecting meristem growth and potential in Petunia hybrida Vilm. J. Hered. 87, 371-377.

Nelson, D. R., Schuler, M. A., Paquette, S. M., Werck-Reichhart, D., and Bak, S. (2004). Comparative genomics of rice and Arabidopsis. Analysis of 727 cytochrome P450 genes and pseudogenes from a monocot and a dicot. Plant Physiol. 135, 756-772.

Pfaffl, M. W. (2001). A new mathematical model for relative quantification in real-time RT-PCR. Nucleic Acids Res. 29, e45.

Ruijter, J. M., Ramakers, C., Hoogaars, W. M. H., Karlen, Y., Bakker, O., Van Den Hoff, M. J. B., and Moorman, A. F. M. (2009). Amplification efficiency: linking baseline and bias in the analysis of quantitative PCR data. Nucleic Acids Res. 37, e45.

Shen, H., Luong, P., and Huq, E. (2007). The F-box protein MAX2 functions as a positive regulator of photomorphogenesis in Arabidopsis. Plant Physiol. 145, 1471-1483.
Siame, B. A., Weerasuriya, Y., Wood, K., Ejeta, G., and Butler, L. G. (1993). Isolation of strigol, a germination stimulant for Striga asiatica, from host plants. J. Agric. Food Chem. 41, 1486-1491.

Simons, J. L., Napoli, C. A., Janssen, B. J., Plummer, K. M., and Snowden, K. C. (2007). Analysis of the DECREASED APICAL DOMINANCE genes of petunia in the control of axillary branching. Plant Physiol. 143, 697-706.

Snowden, K., and Napoli, C. (2003). A quantitative study of lateral branching in petunia. Funct. Plant Biol. 30, 987-994.

Snowden, K., Simkin, A., Janssen, B., Templeton, K., Loucas, H., Simons, J., Karunairetnam, S., Gleave, A., Clark, D., and Klee, H. (2005). The decreased apical dominancel/Petunia hybrida CAROTENOID CLEAVAGE DIOXYGENASE8 gene affects branch production and plays a role in leaf senescence, root growth, and flower development. Plant Cell 17, 746-759.

Snowden, K. C., and Napoli, C. A. (1998). Psl: a novel Spm-like transposable element from Petunia hybrida. Plant J. 14, 43-54.

Sorefan, K., Booker, J., Haurogne, K., Goussot, M., Bainbridge, K., Foo, E., Chatfield, S., Ward, S., Beveridge, C., Rameau, C., and Leyser, O. (2003). MAX4 and RMS1 are orthologous dioxygenase-like genes that regulate shoot branching in Arabidopsis and pea. Genes Dev. 17, 1469-1474.

Stafstrom, J. P. (1995). "Developmental potential of shoot buds," in Plant Stems: Physiology and Functional Morphology, ed B. Gartner (San Diego: Academic Press), 257-279.

Stirnberg, P., Chatfield, S. P., and Leyser, H. M. O. (1999). AXR1 acts after lateral bud formation to inhibit lateral bud growth in Arabidopsis. Plant Physiol. 121, 839-847.
Stirnberg, P., Furner, I. J., and Leyser, H. M. O. (2007). MAX2 participates in an SCF complex which acts locally at the node to suppress shoot branching. Plant J. 50, 80-94.

Stirnberg, P., Van De Sande, K., and Leyser, H. M. O. (2002). MAX1 and MAX2 control shoot lateral branching in Arabidopsis. Development 129, 1131-1141.

Umehara, M., Hanada, A., Yoshida, S., Akiyama, K., Arite, T., TakedaKamiya, N., Magome, H., Kamiya, Y., Shirasu, K., Yoneyama, K., Kyozuka, J., and Yamaguchi, S. (2008). Inhibition of shoot branching by new terpenoid plant hormones. Nature 455, 195-200.

Vandesompele, J., De Preter, K., Pattyn, F., Poppe, B., Van Roy, N., De Paepe, A., and Speleman, F. (2002). Accurate normalization of real-time quantitative RT-PCR data by geometric averaging of multiple internal control genes. Genome Biol. 3. doi: 10.1186/gb-2002-3-7research0034. [Epub ahead of print].

Woo, H. R., Chung, K. M., Park, J.-H., Oh, S. A., Ahn, T., Hong, S. H., Jang, S. K., and Nam, H. G. (2001). ORE9, an F-box protein that regulates leaf senescence in Arabidopsis. Plant Cell 13, 1779-1790.

Xu, G., Ma, H., Nei, M., and Kong, H (2009). Evolution of F-box genes in plants: different modes of sequence divergence and their relationships with functional diversification. Proc. Natl. Acad. Sci. U.S.A. 106, 835-840.

Yokota, T., Sakai, H., Okuno, K. Yoneyama, K., and Takeuchi, Y. (1998). Alectrol and orobanchol, germination stimulants for Orobanche minor, from its host red clover. Phytochemistry 49, 1967-1973.

Yoneyama, K., Xie, X., Sekimoto, H., Takeuchi, Y., Ogasawara, S., Akiyama, K., Hayashi, H., and Yoneyama, K. (2008). Strigolactones, host recognition signals for root parasitic plants and arbuscular mycorrhizal fungi, from Fabaceae plants. New Phytol. 179, 484-494.

Zenoni, S., D'agostino, N., Tornielli, G. B., Quattrocchio, F., Chiusano, M. L., Koes, R., Zethof, J., Guzzo, F., Delledonne, M., Frusciante, L., Gerats, T., and Pezzotti, M. (2011). Revealing impaired pathways in the an 11 mutant by high-throughput characterization of Petunia axillaris and Petunia inflata transcriptomes. Plant J. 68, 11-27.

Zou, J., Chen, Z., Zhang, S., Zhang, W., Jiang, G., Zhao, X., Zhai, W., Pan, X., and Zhu, L. (2005). Characterizations and fine mapping of a mutant gene for high tillering and dwarf in rice (Oryza sativa L.). Planta 222, 604-612.

Conflict of Interest Statement: The authors declare that the research was conducted in the absence of any commercial or financial relationships that could be construed as a potential conflict of interest.

Received: 08 July 2011; accepted: 26 December 2011; published online: 10 January 2012.

Citation: Drummond RSM, Sheehan H, Simons JL, Martínez-Sánchez NM, Turner RM, Putterill $J$ and Snowden KC (2012) The expression of petunia strigolactone pathway genes is altered as part of the endogenous developmental program. Front. Plant Sci. 2:115. doi: 10.3389/fpls.2011.00115

This article was submitted to Frontiers in Plant Evolution and Development, a specialty of Frontiers in Plant Science. Copyright () 2012 Drummond, Sheehan, Simons, Martínez-Sánchez, Turner, Putterill and Snowden. This is an open-access article distributed under the terms of the Creative Commons Attribution Non Commercial License, which permits noncommercial use, distribution, and reproduction in other forums, provided the original authors and source are credited. 


\section{APPENDIX}
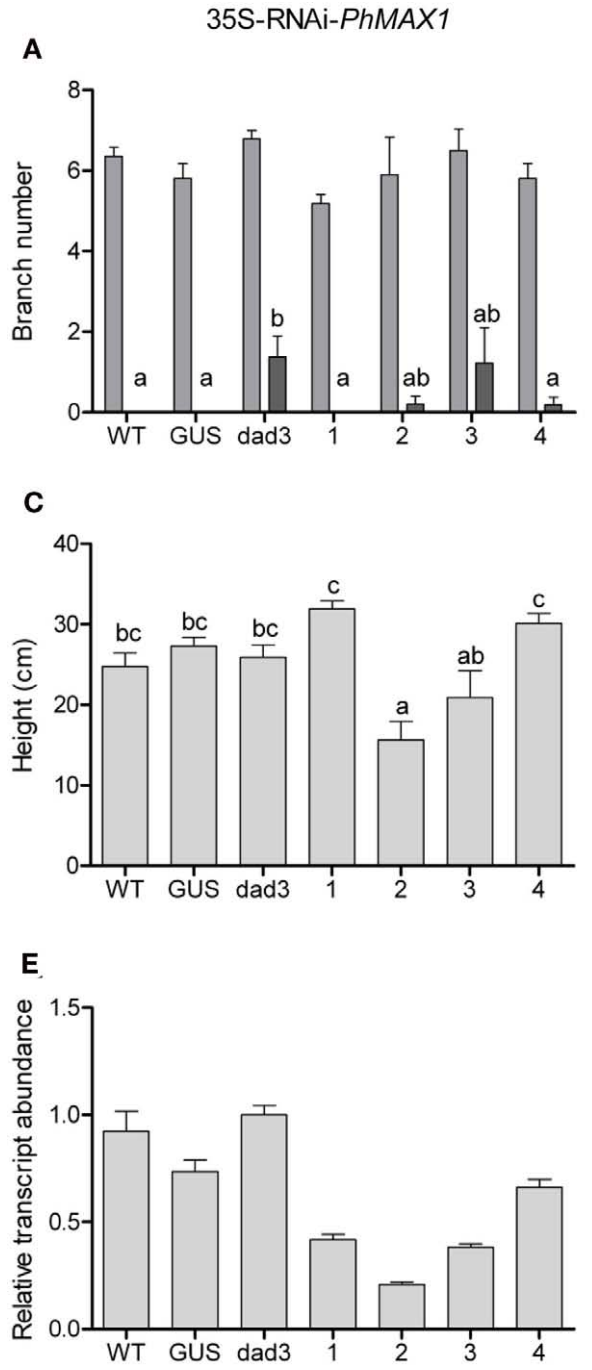

FIGURE A1 | Branching phenotype and target gene transcript levels in petunia PhMAX1 or PhMAX2A RNAi lines. After selection on

kanamycin-containing media 13 lines of $\mathrm{V} 26$ petunia carrying the PhMAX1 RNAi hairpin construct and 19 lines carrying the equivalent PhMAX2A construct were transferred to soil in a greenhouse. Of these lines only four PhMAX1 RNAi lines and three PhMAX2A RNAi lines showed any indication of increased branching. These plants were self crossed and the seeds sown to soil in the glasshouse. These plants were tested for the presence of the transgene by PCR and those plants not carrying the transgene excluded from further analysis. The PhMAX1 RNAi lines were grown along with wild-type, 35S:GUS, and dad3 control plants. Separately the PhMAX2A RNAi lines were grown with wild-type and $35 \mathrm{~S}$ :GUS control plants. The number of primary and secondary branches and plant height was recorded for each plant at

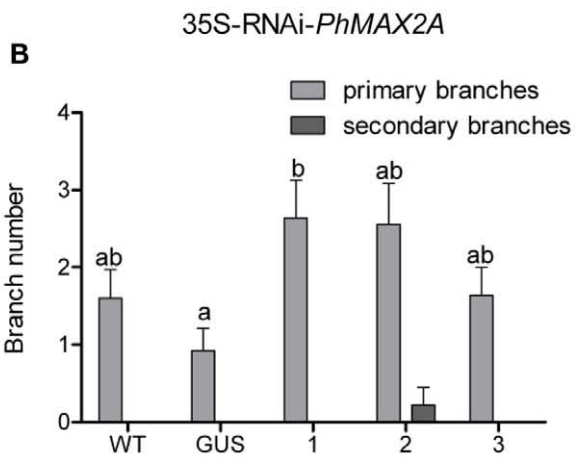

D
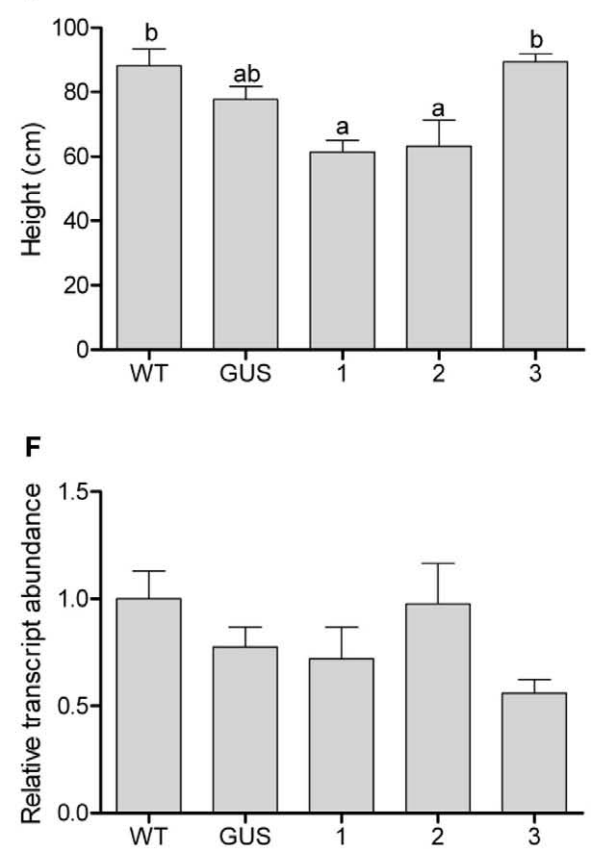

approximately 8 weeks of age for $\operatorname{PhMAX1}(\mathbf{A}, \mathbf{C})$ and approximately 12 weeks of age for PhMAX2A (B,D), values are means \pm SEM $(n \geq 7)$. The branching data $(\mathbf{A}, \mathbf{B})$ are shown as the number of primary branches (light gray bars) and secondary branches (dark gray bars). Separate statistical tests were done for primary and secondary branches. Different lowercase letters indicate statistically significant differences $(P=0.05)$. The results for the statistical tests performed on the data for the number of primary branches in $(\mathbf{A})$ and the numbers of secondary branches in $(\mathbf{B})$ are not shown as no means were found to be significantly different from each other $(P=0.05)$. Samples (leaf for PhMAX2A, low stem for PhMAX1) were taken from six plants of each line, pooled, and the RNA extracted. The relative transcript abundance of PhMAX1 (E) or PhMAX2A (F) was quantified by qPCR as described in the methods, although with only technical replication. 